\section{OPEN ACCESS}

Edited by:

Fan Wang,

University of Technology

Sydney, Australia

Reviewed by:

Karl Zhanghao,

Southern University of Science and

Technology, China

Hao Xie,

Tsinghua University, China

Chaohao Chen,

ETH Zürich, Switzerland

${ }^{*}$ Correspondence:

Xiang HaO

haox@zju.edu.cn

Specialty section:

This article was submitted to

Analytical Chemistry,

a section of the journal

Frontiers in Chemistry

Received: 01 September 2020 Accepted: 14 December 2020

Published: 15 January 2021

Citation:

Han Y, Zhang Z, Liu W, Yao Y, Xu Y, Liu X, Kuang $C$ and Hao $X$ (2021) A

Labeling Strategy for Living Specimens in

Long-Term/Super-Resolution

Fluorescence Imaging.

Front. Chem. 8:601436

doi: 10.3389/fchem.2020.601436

\title{
A Labeling Strategy for Living Specimens in Long-Term/Super-Resolution Fluorescence Imaging
}

\author{
Yubing Han ${ }^{1}$, Zhimin Zhang ${ }^{1}$, Wenjie Liu ${ }^{1}$, Yuanfa Yao ${ }^{2}$, Yingke Xu ${ }^{2}$, Xu Liu ${ }^{1,3,4}$, \\ Cuifang Kuang ${ }^{1,3,4}$ and Xiang Hao ${ }^{1 *}$
}

' State Key Laboratory of Modern Optical Instrumentation, College of Optical Science and Engineering, Zhejiang University, Hangzhou, China, ${ }^{2}$ Department of Biomedical Engineering, Key Laboratory of Biomedical Engineering of Ministry of Education, Zhejiang Provincial Key Laboratory of Cardio-Cerebral Vascular Detection Technology and Medicinal Effectiveness Appraisal, Zhejiang University, Hangzhou, China, ${ }^{3}$ Ningbo Research Institute, Zhejiang University, Ningbo, China,

${ }^{4}$ Collaborative Innovation Center of Extreme Optics, Shanxi University, Taiyuan, China

Despite the urgent need to image living specimens for cutting-edge biological research, most existing fluorescent labeling methods suffer from either poor optical properties or complicated operations required to realize cell-permeability and specificity. In this study, we introduce a method to overcome these limits-taking advantage of the intrinsic affinity of bright and photostable fluorophores, no matter if they are supposed to be live-cell incompatible or not. Incubated with living cells and tissues in particular conditions (concentration and temperature), some Atto and BODIPY dyes show live-cell labeling capability for specific organelles without physical cell-penetration or chemical modifications. Notably, by using Atto $647 \mathrm{~N}$ as a live-cell mitochondrial marker, we obtain 2.5-time enhancement of brightness and photostability compared with the most commonly used SiR dye in long-term imaging. Our strategy has expanded the scientist's toolbox for understanding the dynamics and interactions of subcellular structures in living specimens.

\footnotetext{
Keywords: super-resolution microscopy, organic fluorescent dye, long-term imaging, living specimens, subcellular structures
}

\section{INTRODUCTION}

Biologists rely on an array of fluorescent microscopy to observe morphologies and dynamics in living cells, which is crucial in interpreting vital physiological and pathological activities. However, although dramatic improvements have been implemented since the seminal discovery of fluorophores and their applications in microscopy (Miyawaki et al., 2003; Specht et al., 2017), it is still quite challenging to achieve live-cell specific staining simultaneously with high brightness and photostability.

In fact, most live-cell labeling methods, including fluorescent proteins (Mishin et al., 2015), chemical tag techniques using cell-permeable fluorescent dyes [e.g., SNAP-Cell 647-SiR (Lukinavičius et al., 2015)], and live-cell organic fluorescent probes [e.g., MitoTracker dyes (Chazotte, 2011)], suffer from relatively low brightness and photostability (Fernandez-Suarez and Ting, 2008; Han et al., 2017). Low optical properties of the fluorescent probes may 
lead to low signal-to-noise ratios (SNR) and fast photobleaching, while low SNR reduces the quality of the microscope images or may even introduce artifacts. Worse still, is that the photobleaching is undesirable in long-term experiments. A dosage increase can partially remedy this problem, but it may also lead to non-specific labeling (Han et al., 2017; Shen et al., 2018). Another option is to increase the illumination laser power, but it, in turn, further accelerates the photobleaching and introduces stronger phototoxicity. This issue stands out especially in imaging methods for more information in multiple dimensions (e.g., high spatiotemporal resolution, long acquisition times, and large volume imaging) (Jaiswal et al., 2003; Fernandez-Suarez and Ting, 2008; Ji et al., 2016).

In the past few decades, various types of commercially available dyes, with exceptionally excellent brightness and photostability, have been developed and are widely used in cells and organisms (Chazotte, 2011; Sigal et al., 2018). Although several dyes have been proven to be efficient in livecell super-resolution imaging (Lukinavicius et al., 2014; Yang et al., 2020), most of these fluorophores were supposed to be "live-cell incompatible" (Mao et al., 2020). Their intracellular cytosolic delivery and labeling specifically, rely heavily on specific physical or chemical methods, such as microinjection, encapsulating vesicles, or chemical modifications using cellpenetrating peptides (Erazo-Oliveras et al., 2014; Hennig et al., 2015; Han et al., 2017).

Following our previous work, which demonstrated the livecell mitochondrial labeling capacity of Atto 647N (Han et al., 2017), here we prove that Atto $647 \mathrm{~N}$ is not an individual case and that there is a general pattern behind it. We present a strategy to label living cells and tissues using commercially available dyes that were supposed to be "incompatible" for live-cell labeling (von Provazek, 1914; Bosch et al., 2014). The transition from "incompatible" to "compatible" is based on discovering and utilizing the intrinsic affinity of the dyes to subcellular structures in living cells when working at micromolar-level concentrations. Specifically, by incubating with living specimens at $1.5-15 \mu \mathrm{M}$ for $30 \mathrm{~min}$ at $37^{\circ} \mathrm{C}$ or $20^{\circ} \mathrm{C}$, the "live-cell incompatible" dyes can also be used for live-cell labeling, without needing complicated chemical modifications or physical operations during the entire process. Using our labeling strategy, these commercially available dyes, especially Atto 647N NHS ester, shows great potential as a live-cell mitochondrial marker in long-term, three-dimensional (3D), and super-resolution imaging.

\section{MATERIALS AND METHODS}

\section{Primary Cultural Astrocytes}

Primary cultural astrocytes were obtained from Sprague-Dawley (SD) rat brains (1 day old). The rats were bought from the Zhejiang Research Center of Laboratory Animals, China, sterilized with $75 \%$ ethanol, and sacrificed by decapitation. The following steps were all done on ice. The scalps and skulls were incised, and the brains were taken out and placed into precooling Phosphate buffered saline (PBS; Thermo Fisher Scientific, Inc.). The cortex was then isolated, cut into pieces using knives, and incubated with pre-warmed Trypsin-EDTA (Thermo Fisher
Scientific, Inc.) at $37^{\circ} \mathrm{C}$ for $20 \mathrm{~min}$. The mixture was centrifuged for $5 \mathrm{~min}$ at $1,000 \mathrm{rpm}$, and the supernatant was removed. The cells were then dissociated by adding $5 \mathrm{~mL}$ of pre-warmed growth medium (DMEM, high glucose $+10 \%$ fetal bovine serum (FBS); Thermo Fisher Scientific, Inc.), followed by vigorous pipetting. Finally, the cell suspension was incubated in a T25 flask (Thermo Fisher Scientific, Inc.) at $37^{\circ} \mathrm{C}$ in a humidified $5 \% \mathrm{CO}_{2}$ environment. The medium was changed every 2 days, and after $7 \sim 8$ days, the culture flask was shaken manually for 30 min to remove the overlaying microglia exposed on the astrocyte layer. The supernatant containing microglia was discarded, and $5 \mathrm{~mL}$ of culture medium was added into the flask. This step was repeated once to remove oligodendrocyte precursor cells.

\section{Cell Culture}

HeLa (human adenocarcinoma cell line), HEK293 (human embryonic kidney epithelial cell line), NIH/3T3 (mouse embryonic fibroblast cell line), and U2OS (human osteosarcoma cell line) cells were purchased from the American Type Culture Collection. HeLa, HEK293, and NIH/3T3 cells were cultured in the DMEM medium (Thermo Fisher Scientific, Inc.). U2OS cells were cultured in McCoy's 5A medium (Thermo Fisher Scientific, Inc.). All media were supplemented with $10 \%(\mathrm{v} / \mathrm{v})$ FBS, and the cultures were maintained at $37^{\circ} \mathrm{C}$ in a humidified $5 \% \mathrm{CO}_{2}$ environment.

\section{Transfection}

Cells were grown overnight in 24 -well plates at $37^{\circ} \mathrm{C}$ in a $5 \% \mathrm{CO}_{2}$ atmosphere. After reaching over $80 \%$ confluence, the plasmids mRuby-Clathrin (Addgene \#55852), pEGFPSec23A (Addgene \#66609), ZsGreen-Rab5 (custom synthesized by Genomeditech (Shanghai, China) Co., Ltd.), EGFP-Rab7A (Addgene \#28047), GFP-LAMP1 (Addgene \#16290), EMTB3XGFP (Addgene \#26741), pSNAPf-Cox8A (Addgene \#101129), or pSNAPf-TOMM20 (custom synthesized by Genomeditech (Shanghai, China) Co., Ltd.) was transfected into the cells using Lipofectamine 3000 (Thermo Fisher Scientific, Inc.) according to the manufacturer's instructions. After $24 \mathrm{~h}$, the transfected cells were digested with trypsin-EDTA and seeded into Nunc Glass Bottom Dishes ( $\Phi 12 \mathrm{~mm}$, Thermo Fisher Scientific, Inc.) at a density of $1.5 \sim 2.0 \times 10^{4}$ per well in growth medium (150 $\mu \mathrm{L}$ ). The cells were grown for an additional $12 \sim 24 \mathrm{~h}$ before incubation with the indicated probes.

\section{Live-Cell Labeling With Commercially Available Probes}

Before staining, the indicated cells were seeded in Nunc Glass Bottom Dishes at a density of $1.5 \sim 2.0 \times 10^{4}$ per well in growth medium $(150 \mu \mathrm{L})$. After overnight incubation, the cells were washed three times with PBS. Working solutions of the indicated probes at different concentrations were prepared with phenol red-free DMEM (Thermo Fisher Scientific, Inc.). The cells were then incubated with MitoTracker Deep Red FM (200-500 nM, $100 \mu \mathrm{L}$; Thermo Fisher Scientific, Inc.), MitoTracker Green FM (1,000 nM, $100 \mu \mathrm{L}$; Thermo Fisher Scientific, Inc.), SiR-actin (Cytoskeleton, Inc.), and DiO $(5 \mu \mathrm{M}$, $100 \mu \mathrm{L}$; Beyotime Biotechnology) in a $5 \% \mathrm{CO}_{2}$ atmosphere at 
$37^{\circ} \mathrm{C}$ for $30 \mathrm{~min}$. For SNAP-Cell 647-SiR (New England Biolabs, Inc.) dye labeling, transfection of pSNAPf-Cox8A or pSNAPfTOMM20 was performed before incubation of SNAP-Cell 647$\operatorname{SiR}(3 \mu \mathrm{M})$ at $37^{\circ} \mathrm{C}$ for $30 \mathrm{~min}$. After incubation, the supernatant was discarded, and a solution of Trypan blue (TB, $100 \mu \mathrm{L}$, $1 \mathrm{mg} \mathrm{mL}{ }^{-1}$; Sigma-Aldrich Co., LLC) in PBS was added to exclude the dead cells and quench the extracellular fluorescence from the probes bound to either the cell membrane or the dish surface (Manceur et al., 2007; Cottet-Rousselle et al., 2011; Han et al., 2017). After $1 \mathrm{~min}$, TB was removed, and the cells were washed twice gently with PBS. Cells were immersed in Live Cell Imaging Solution (Thermo Fisher Scientific, Inc.) before imaging. ProLong Live Antifade Reagent (Thermo Fisher Scientific, Inc.) was added to this solution according to the manufacturer's instructions when required.

\section{Live-Cell Labeling With Fluorescent Dyes}

Before staining, the indicated cells were seeded in Nunc Glass Bottom Dishes at a density of $1.5 \sim 2.0 \times 10^{4}$ per well in growth medium $(150 \mu \mathrm{L})$. After overnight incubation, the cells were washed three times with PBS. Aliquots of Atto 495, Atto 565, Atto 590, Atto 647N (Sigma-Aldrich Co., LLC), BODIPY 650/665, Alexa Fluor 647 (Thermo Fisher Scientific, Inc.), Cy3B, and Cy5 (GE Healthcare Co., Ltd) NHS esters were dissolved in Dimethyl sulfoxide (DMSO; Sigma-Aldrich Co., LLC) to make 3-mM stock solutions at $-20^{\circ} \mathrm{C}$. Stock solutions were diluted with phenol red-free DMEM to work solutions at different concentrations before use. The cells were incubated with these dyes either at $37^{\circ} \mathrm{C}$ in a $5 \% \mathrm{CO}_{2}$ atmosphere or at $20^{\circ} \mathrm{C}$ for $30 \mathrm{~min}$. The postincubation treatment was the same as that of the commercially available probes above.

The organic probes Dye-Lyso, Dye-Tubulin, and Dye-Actin were constructed in two parts. One part contains the recognition unit (epoxysuccinyl scaffold (Han et al., 2017), docetaxel (Lukinavicius et al., 2018), and Lifeact (Han et al., 2019), the cellpenetrating peptide $(r R)_{3} R_{2}$, and a short peptide GKGKGK (in which lysine offers free active amino groups available to conjugate with commercially available dyes via an NHS group). The other part is a commercially available fluorescent dye containing an NHS group. Covalent bonds link these two parts to form an entire probe. The first part was later purified by preparative high-performance liquid chromatography (HPLC) to $>95 \%$ after being prepared by solid-phase peptide synthesis. Its mass was confirmed by electrospray ionization mass spectrometry (EIMS). Before being conjugated to the dyes, the peptide part was dissolved in bicarbonate buffer $(0.1 \mathrm{M}, \mathrm{pH} 8.3)$ at a $1 \mathrm{mM}$ concentration and stored at $4^{\circ} \mathrm{C}$. For the conjugation, an aliquot of each dye was dissolved with $10-20 \mu \mathrm{L}$ of DMSO added to $14 \mu \mathrm{L}$ of the peptide part solution and mixed thoroughly. The mixture was allowed to react at room temperature overnight with constant shaking. The mixture was then purified using Pierce C18 Spin columns (Thermo Fisher Scientific, Inc.) according to the manufacturer's instructions. After purification, the supernatant was evaporated to dryness in a vacuum centrifuge, and the residue was dissolved in $200 \mu \mathrm{L}$ of Phosphate Buffered Saline (PBS, pH 7.4; Thermo Fisher Scientific, Inc.) to generate a stock solution of the indicated probes.
Filipin (Meilunbio) and Cytochalasin D (Aladdin) were dissolved in DMSO to make 1-mM stock solutions, which were diluted with phenol red-free DMEM to working solutions at different concentrations before use. The cells were incubated with the drug solutions for $30 \mathrm{~min}$ at $37^{\circ} \mathrm{C}$ in a $5 \% \mathrm{CO}_{2}$ atmosphere before Atto 565 labeling.

\section{Labeling Living Tissue Slices With Fluorescent Probes}

All animal procedures were conducted in compliance with the guidelines for animal care and use of Zhejiang University and conformed to the Guide for the Care and Use of Laboratory Animals published by the National Academy Press (Washington, DC, 1996). The 12-week-old Institute of Cancer Research (ICR) mice were obtained from Zhejiang Academy of Medical Sciences [License Number: SCXK (Zhe) 2014001] and housed in cages under a standard condition of temperature $\left(23 \pm 2^{\circ} \mathrm{C}\right)$, relative humidity $(55 \pm 5 \%)$, and a light $12 / 12 \mathrm{~h}$ light/dark cycle. The mice had free access to food and water. Before the experiment, the mice were sacrificed by euthanasia. The brains were separated and washed with cold PBS buffer. The brains were then cut into slices from different orientations and incubated with Atto $647 \mathrm{~N}$ $(15 \mu \mathrm{M})$ for $30 \mathrm{~min}$ at $37^{\circ} \mathrm{C}$. After incubation, the supernatant was discarded, and the tissue slices were washed twice gently with PBS. The tissue slices were then put on the Nunc Glass Bottom Dishes with the wound surface toward the glass bottom.

\section{Cell Viability}

The Atto dyes' cytotoxicity on different cell lines was tested using the 3-(4,5-dimethylthiazol-2-yl)-5-(3-carboxymethoxyphenyl)2-(4-sulfophenyl)-2H-tetrazolium (MTS) assay (Cory et al., 1991). Cells $\left(3-4 \times 10^{3}\right.$ cells per well) were seeded into a 96well plate and cultured in the growth medium for $24 \mathrm{~h}$. The cells were incubated with the dyes $(1.5 \mu \mathrm{M}$ or $15 \mu \mathrm{M})$ in a $5 \% \mathrm{CO}_{2}$ atmosphere at $20^{\circ} \mathrm{C}$ or $37^{\circ} \mathrm{C}$ for $30 \mathrm{~min}$, washed twice gently with $\mathrm{PBS}$, and incubated in the growth medium for $3 \mathrm{~h}$ at $37^{\circ} \mathrm{C}$. The cells were then immersed in $100 \mu \mathrm{L}$ of growth medium and $20 \mu \mathrm{L}$ of CellTiter 96 AQueousOne Solution Reagent (Promega Co.) for another $1 \mathrm{~h}$ at $37^{\circ} \mathrm{C}$, and the absorbance was recorded at $492 \mathrm{~nm}$ using a TECAN GENios Plus ELISA reader (Tecan, Inc.). The cell viabilities were expressed as the percentage of the A492 of the dye-treated cells to the untreated controls. The A492 of the dyes themselves, tested in cells without MTS treats, were subtracted in the treated cells. All the measurements were performed in triplicate.

\section{pH Sensitivity of Atto 565}

Solutions of Atto 565 at different $\mathrm{pH}$ were diluted from the stock solution (see Section Live-cell labeling with fluorescent dyes) with citric acid or sodium hydroxide solutions at certain concentrations (Sigma-Aldrich Co., LLC). The fluorescence intensity was recorded $\left(\lambda_{\text {ex }}=563 \mathrm{~nm}\right)$ using a SpectraMax M2e (Molecular Devices, LLC.).

\section{Confocal Laser Scanning Microscopy}

The confocal images were obtained using a C2 confocal laser scanning microscope (Nikon, Inc.) equipped with a $100 \times / 1.49$ 
numerical aperture (NA) oil immersion objective lens and were analyzed with NIS-elements (Nikon, Inc.) and ImageJ software (National Institutes of Health).

\section{STED Microscopy}

The STED images were obtained using a STEDYCON microscope (Abberior, GmbH.) equipped with a $100 \times / 1.49$ NA oil immersion objective lens. A $40-\mathrm{MHz}$ pulsed laser $(775 \mathrm{~nm})$ was used for depletion. The depletion laser intensity on the back-pupil plane was measured as about $80 \mathrm{~mW}$. The depletion time was set as $1.2 \mathrm{~ns}$, and the time gating was set as 1-7 ns. The resolution was calculated with the system's built-in software as $37 \mathrm{~nm}$, using 40-nm red fluorescent beads (Abberior, GmbH.). Pinhole: $64 \mu \mathrm{m}$. For Figure 4B, the pixel size is $50 \mathrm{~nm}$, and the pixel dwell time is $4 \mu \mathrm{s}$; for Figures $4 \mathrm{C}, \mathrm{E}$, the pixel size is $20 \mathrm{~nm}$, and the pixel dwell time is $10 \mu \mathrm{s}$ (STED) and 10 $\mu \mathrm{s}$ (Confocal).

\section{RESULTS}

\section{Evaluation of Atto Dyes for Labeling Living Cells}

Several types of fluorescent dyes were characterized according to their structure series.

Many cell-permeable cationic dyes (e.g., Rhodamine and Carbocyanine derivates) have been developed as mitochondrial probes, as they tend to accumulate in the mitochondrial matrix driven by the potential gradient in mitochondria at about 100nM concentrations (Chazotte, 2011; Cottet-Rousselle et al., 2011; $\mathrm{Xu}$ et al., 2016). Endoplasmic reticulum (ER) staining can also be realized by raising the dosages of these dyes (Han et al., 2017). However, for the "live-cell compatible" dyes, concentrations at the 100-nM level are not enough.

Four Rhodamine derivatives, i.e., Atto 495, Atto 565, Atto 590, and Atto 647N N-Hydroxysuccinimide (NHS) esters, were investigated due to their relatively good optical properties in the corresponding spectral bands (Figure 1; Supplementary Figures 1-6). When incubated at $37^{\circ} \mathrm{C}$, which is the optimal temperature for cell cultures, both mitochondrialike and bright dot signals inside the cells were observed (Supplementary Figure 1B); whereas when the incubation temperature was set to $20^{\circ} \mathrm{C}$ (room temperature), the dot signals were dramatically reduced (Supplementary Figure 1C).

For the mitochondria-like signals, colocalization experiments using MitoTracker probes were performed to verify the mitochondrial staining, and the Pearson correlation coefficients for Atto 495, Atto 590, and Atto $647 \mathrm{~N}$ were 0.70, 0.57, and 0.82, respectively (Figures 1A-C; Supplementary Figure 2). The results indicate the mitochondrial labeling of Atto 495 and Atto647N.

Furthermore, the dot signals of Atto 565 were partially colocalized with endocytic-associated vesicles (i.e., early endosomes, late endosomes, and lysosomes; Figures 1D,F and Supplementary Figures 3-5), while no macroscopic colocalization was found with endocytic-unassociated vesicular structures (Supplementary Figure 6). After the cells were treated with Filipin and Cytochalasin D, which are known as endocytosis inhibitors (Rodal et al., 1999; Fujimoto et al., 2000; Dutta and Donaldson, 2012), the fluorescence intensity of Atto 565 labeling decreased to $36 \sim 68 \%$ (Supplementary Figure 7 ). These results suggest the dependence of the dot signals on endocytosis to some extent (Figure 1G). The pH sensitivity of Atto 565 was also investigated since most of its signals were discovered in vesicles with an acidic environment (Yamashiro et al., 1983). The results showed that the fluorescence intensity of Atto 565 decreases as the $\mathrm{pH}$ values decline, suggesting that its brightness is limited when caught in endocytic vesicles (Supplementary Figure 8).

\section{Staining Mechanism of Atto 647N and 565 NHS Ester}

For Atto $647 \mathrm{~N}$ NHS ester, which contains two parts (i.e., the cationic dye Atto $647 \mathrm{~N}$ and the NHS moiety), we further investigated its mitochondrial labeling mechanism. Various recognition units (Han et al., 2017) were conjugated to Atto $647 \mathrm{~N}$ to verify the dye's affinity to mitochondria. Probes were named as Atto 647N -Lyso, Atto 647N -Tubulin, and Atto $647 \mathrm{~N}$-Actin according to the recognition units they contain (Figure 2A). Atto 647N NHS ester was taken as a control group. The results showed that the conjugated units did not work, and all the probes labeled mitochondria or ER. Similar tests were performed for Atto 565, too. The results showed that only Atto 565-Actin partially marked actin filaments, and the other Atto 565-probes only labeled vesicle structures (Figure 2B). These results suggest that the affinity competition occurs between the dyes and their conjugated groups, and there is a strong tendency for mitochondria in Atto $647 \mathrm{~N}$ itself, no matter what ligands were bound to it.

Fluorescent cationic dyes that tend to accumulate in mitochondria can be divided into two categories. Without any other active groups (e.g., Rhodamine 123), dyes may fail to stain mitochondria after fixation due to the loss of membrane potential, while with active groups (e.g., MitoTracker probes), dyes can form covalent bonds with mitochondrial membrane proteins (Poot et al., 1996). In our previous tests (Han et al., 2017), Atto 647N NHS ester kept its labeling pattern after fixation, indicating that the NHS ester contributes to the labeling by covalently binding to mitochondrial membrane proteins. The colocalization study employing MitoTracker Green by superresolution imaging, which showed a high fluorescent signal in both inner and outer mitochondrial membranes, further proved this (Han et al., 2017). A recent labeling method, named FLARE also utilizes Atto 647N NHS ester as a mitochondrial marker in fixed cells by the reaction with amines (Mao et al., 2020).

The above results indicate that both the cationic charge of Atto $647 \mathrm{~N}$ and the covalent bonds from the NHS ester contribute to the mitochondrial affinity of Atto $647 \mathrm{~N}$ NHS ester.

\section{Evaluation of the Dyes From Other Series for Live-Cell Labeling}

Then, as Carbocyanine dyes, anionic Alexa Fluor (AF) 647, zwitterionic $\mathrm{Cy} 3 \mathrm{~B}$, and cationic $\mathrm{Cy} 5$ were chosen as representative research objects (Supplementary Figures 9A-C). 

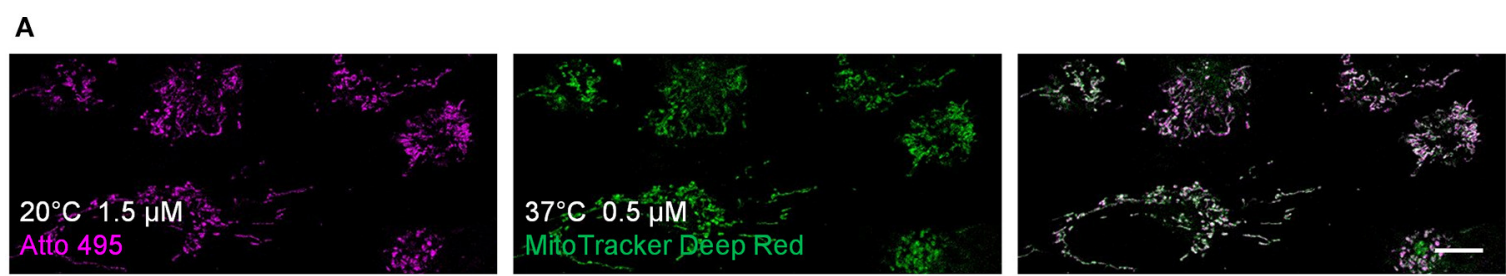

B
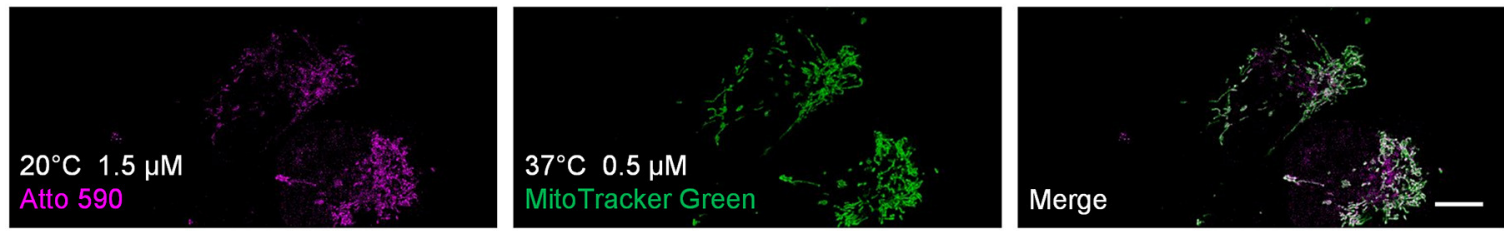

C
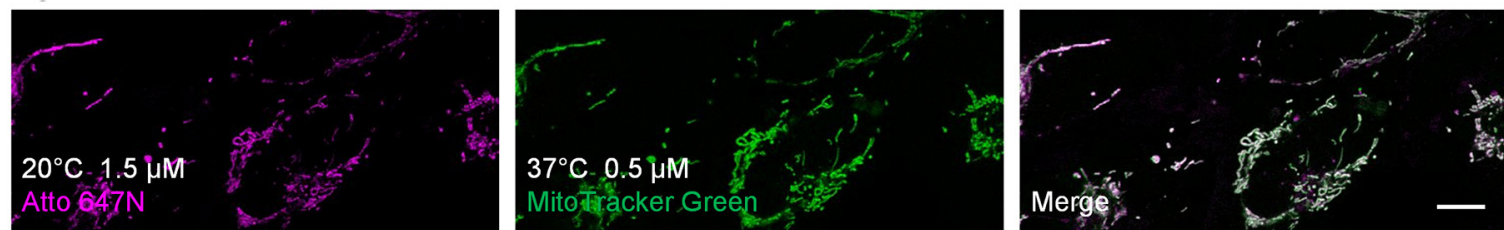

D

E
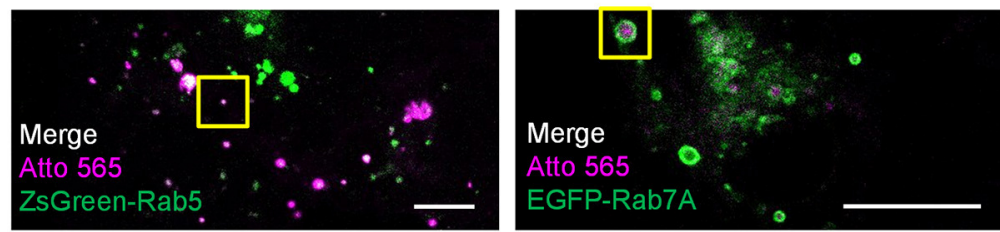

F
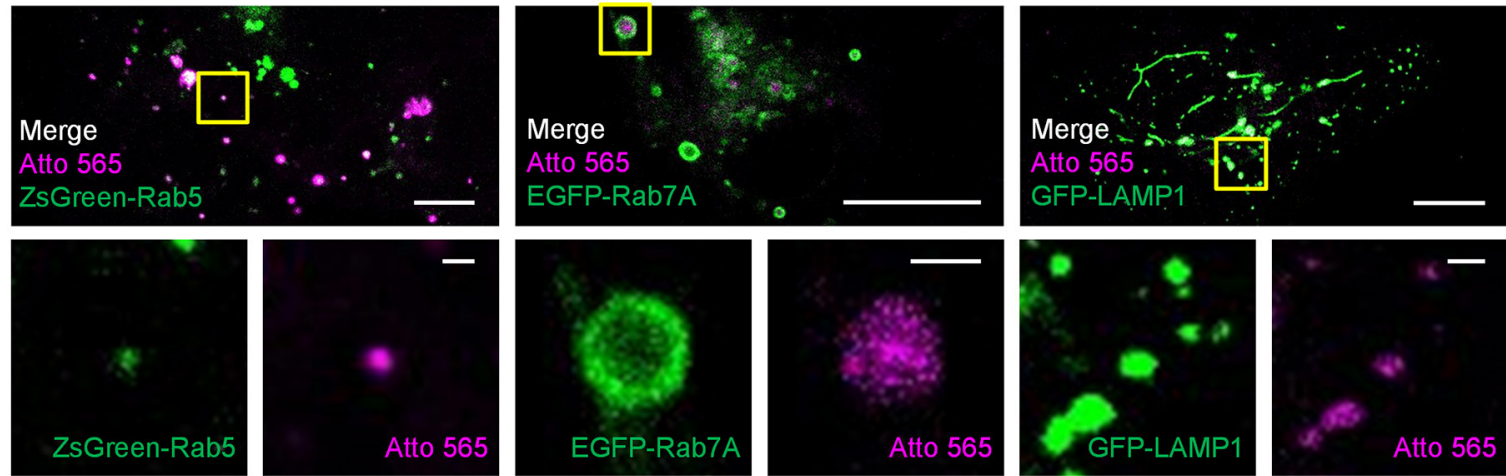

G

Plasma membrane

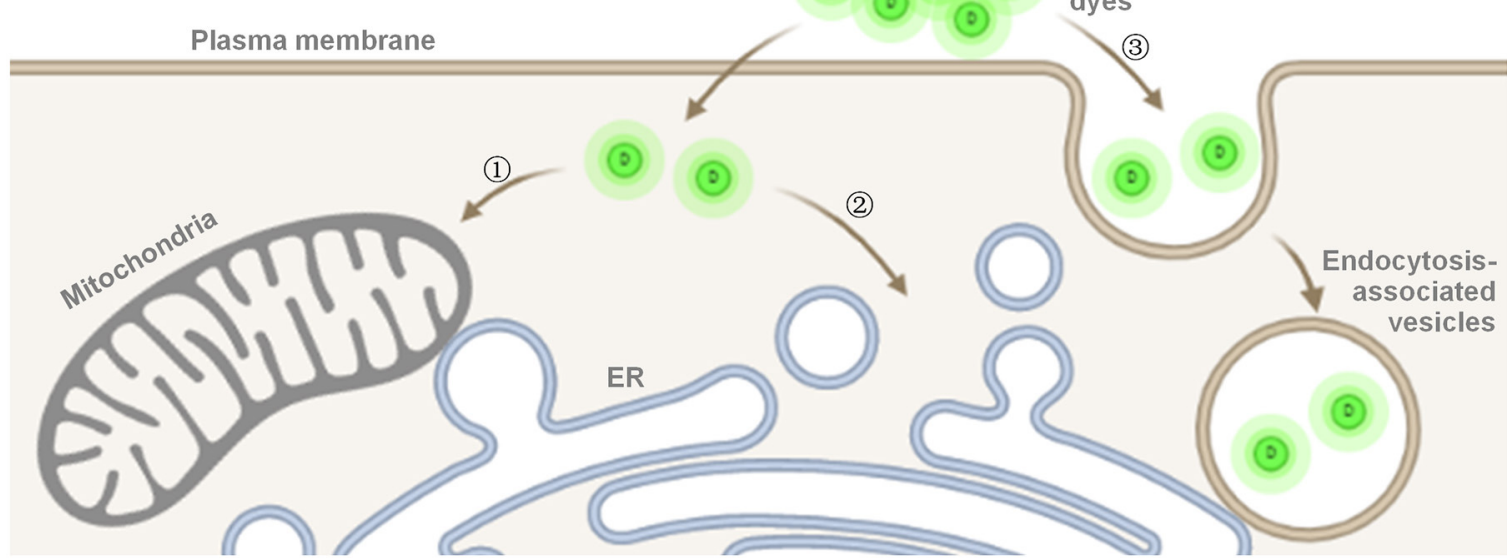

FIGURE 1 | Live-cell labeling of the Atto dyes. Colocalization studies employing different fluorescent probes and proteins as the standard mitochondrial markers. (A) Living U2OS cells were incubated with Atto 495 (magenta, $1.5 \mu \mathrm{M}$ ) for 30 min at $20^{\circ} \mathrm{C}$ and then with MitoTracker Deep Red (green, $0.5 \mu \mathrm{M}$ ) for $30 \mathrm{~min}$ at $37^{\circ} \mathrm{C}$ before imaging. Living U2OS cells were incubated with (B) Atto 590 or (C) Atto $647 \mathrm{~N}$ (magenta, $1.5 \mu \mathrm{M}$ ) for 30 min at $20^{\circ} \mathrm{C}$ and then with MitoTracker Green (green, $0.5 \mu \mathrm{M}$ ) 
FIGURE 1 | for $30 \mathrm{~min}$ at $37^{\circ} \mathrm{C}$ before imaging. Pearson correlation coefficient: 0.70, 0.57, and 0.82 for Atto 495, Atto 590, and Atto 647N, respectively. Living U2OS cells transiently transfected by (D) ZsGreen-Rab5 (green; early endosomes), (E) EGFP-Rab7A (green; late endosomes), and (F) GFP-LAMP1 (green; lysosomes) were stained with Atto 565 (magenta, $6 \mu \mathrm{M}$ ) for $30 \mathrm{~min}$ at $37^{\circ} \mathrm{C}$ and imaged by confocal microscope. Top panels: merged channels; bottom panels: enlarged single-channel images from the yellow boxed regions in the top panels, revealing colocalization of Atto 565 and specific endocytic vesicles. (G) The dyes enter living cells through (1), (2) concentration-dependent free diffusion (e.g., Atto $647 \mathrm{~N}$ ), or (3) endocytosis (e.g., Atto 565). Scale bars, (A-C, upper panels of D-F) $10 \mu \mathrm{m}$, and (lower panels of D-F) $1 \mu \mathrm{m}$.

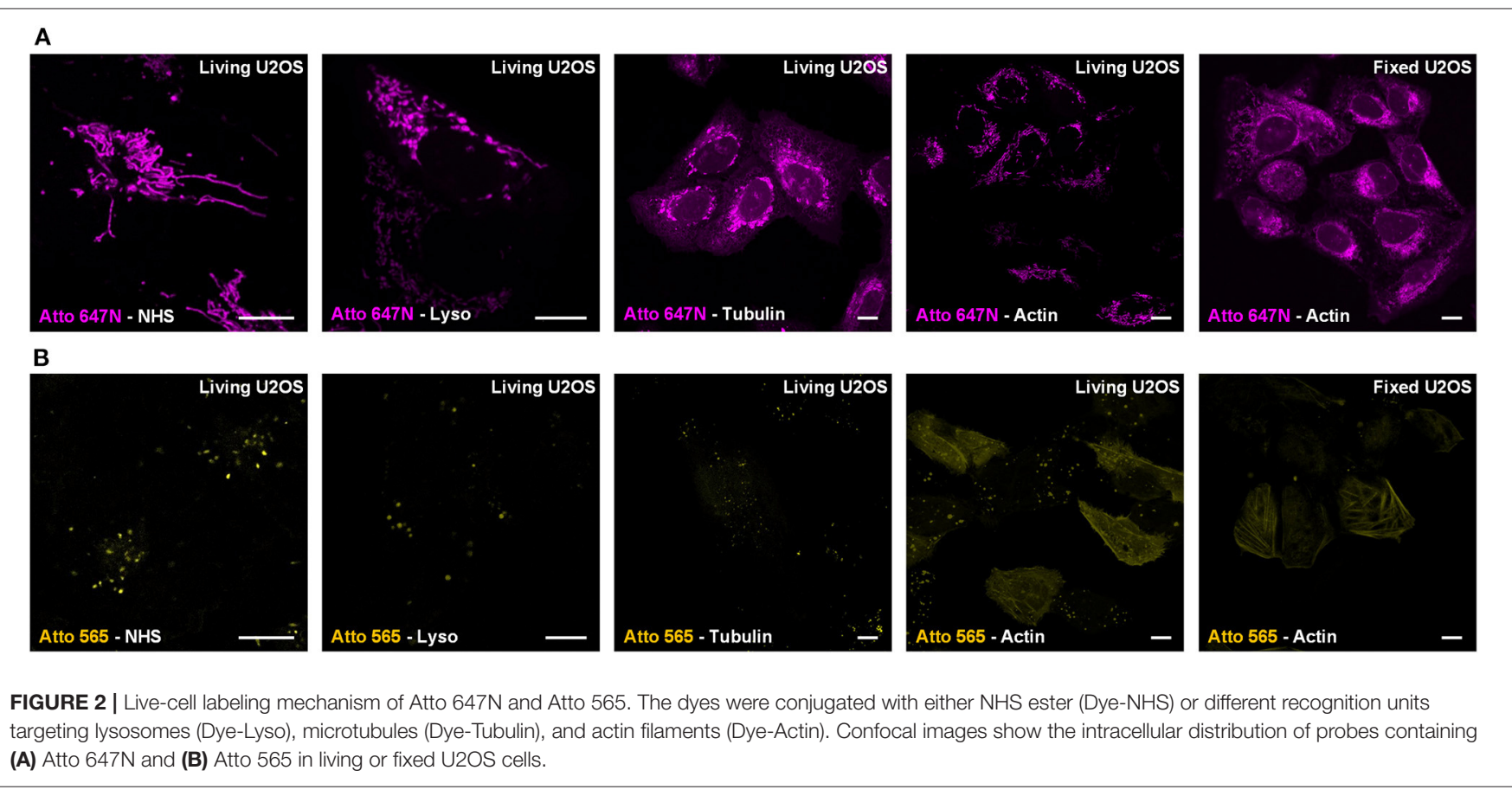

No mitochondrial staining was found after the incubation at either $37^{\circ} \mathrm{C}$ or $20^{\circ} \mathrm{C}$. For $\mathrm{AF} 647$ and $\mathrm{Cy} 3 \mathrm{~B}$, the introduction of sulfonic acid groups improves fluorescence and solubility in water but adds negative charges, preventing their affinity for mitochondria (Wories et al., 1985). For Cy5, the high hydrophobicity leads to a certain degree of affinity for the plasma membrane (Pearson correlation coefficient: 0.52; Supplementary Figures 9B, 10A), preventing its permeation into living cells (Simons et al., 2009).

Unexpectedly, zwitterionic BODIPY 650/665 showed an affinity for mitochondria at a low concentration (300 nM, Pearson correlation coefficient: 0.52; Supplementary Figures 9D, 10B) while labeled ER at a relatively high concentration (15 $\mu \mathrm{M}$, Pearson correlation coefficient: 0.82; Supplementary Figures 9D, 10C) was shown, suggesting its potential as a live-cell ER marker. Our results also indicate the mitochondrial affinity of BODIPY 650/665, breaking through the earlier conclusion (Xu et al., 2016) that this purpose can only be achieved using cationic dyes.

In view of the above observations, we hypothesize that without additional vector reagents and physical penetration, a group of fluorescent dyes, no matter if they were initially considered live-cell compatible or not, can mark subcellular structures in living cells using our labeling strategy (Supplementary Table 1).

\section{Labeling in Various Types of Living Cells}

We also used the living HeLa (human adenocarcinoma cell line), HEK293 (human embryonic kidney epithelial cell line), NIH/3T3 (mouse embryonic fibroblast cell line) cells, and primary cultural astrocytes from 1-day-old Sprague-Dawley (SD) rats (Figure 3; Supplementary Figure 11) to demonstrate the universality of our strategy. Notably, while the transfection in primary cultural astrocytes is challenging to achieve, the incubation with fluorescent probes is quite efficient and straightforward.

Compared with the above-mentioned fluorescent probes containing fluorescent dyes, recognition units, and cellpermeable peptides, which also work at the micromolar level (Han et al., 2017), the cytotoxicity of our method here mainly comes from the dyes themselves and the organic solvent in the incubation buffer (e.g., DMSO). To further confirm that our approach is compatible with the living specimens, the cytotoxicity of this method was then investigated by a 3-(4,5-dimethylthiazol-2-yl)-5-(3-carboxymethoxyphenyl)-2-(4sulfophenyl)-2H-tetrazolium (MTS) assay (Cory et al., 1991). The cell viabilities were expressed as the percentage of the dye-treated cells' absorbance to the untreated controls. All the measurements were performed in triplicate. The results showed that after being treated with the indicated dyes, the cell viabilities usually exceeded $80 \%$ when incubated at $37^{\circ} \mathrm{C}$ and between 
A
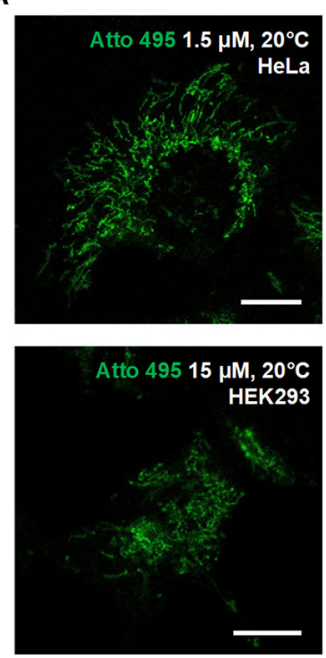

B
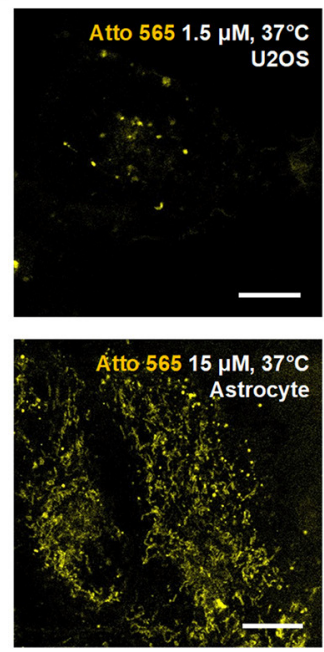

C
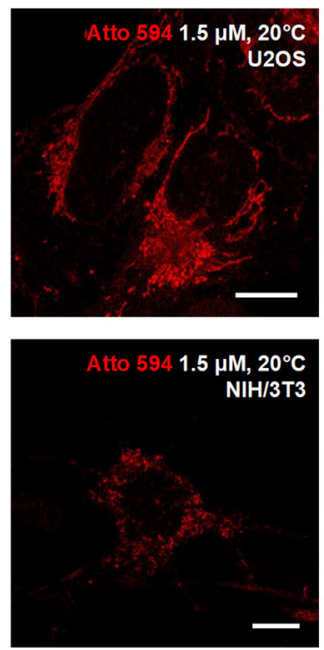

D
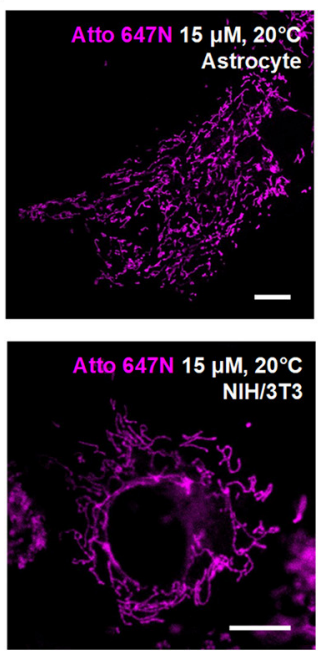

FIGURE 3 | Compatibility of the Atto dyes to various types of living cells. Confocal images of living U2OS, Astrocyte, H3K293, HeLa, and NIH/3T3 cells incubated with (A) Atto 495, (B) Atto 565, (C) Atto 590, and (D) Atto $647 \mathrm{~N}$ at either $37^{\circ} \mathrm{C}$ or $20^{\circ} \mathrm{C}$. Scale bars, $10 \mu \mathrm{m}$.

60 and $90 \%$ when incubated at $20^{\circ} \mathrm{C}$, except in isolated cases (Supplementary Figure 12).

\section{Photostability of Atto 647N}

We quantitatively compared the optical properties of the frequently-used red-absorbing fluorophores. For photostability evaluation, fluorescence intensity curves were extracted from 20-min confocal imaging of U2OS cells (Figure 4A; Supplementary Figure 13), where all the imaging settings (e.g., laser power, size of field-of-view, imaging speed) were retained to control variables (Supplementary Table 2). The power density on the sample was adjusted to $\sim 1.25 \mathrm{~kW}$ $\mathrm{cm}^{-2}$ to ensure that all the probes were bright enough in the first frame. For Atto 647N, whose brightness is 2.50 times that of the SiR dye (Mishin et al., 2015) according to the manufacturers (Supplementary Table 3), the laser power used can be reduced by at least an order of a magnitude. The results showed that: (i) Atto $647 \mathrm{~N}$ kept more than $88 \%$ of its intensity after 20-min of imaging (Supplementary Figure 13A); (ii) incubation of MitoTracker Deep Red at $200 \mathrm{nM}$ (recommended concentration according to the manufacturer's instructions) already exhibited intense non-specific labeling of ER, while the signal intensity of both mitochondria and ER declined rapidly with only 19\% left in the end (Supplementary Figure 13B); (iii) SNAP-Cell $647-$ SiR kept more than $70 \%$ of the intensity in the last frame. However, the cells stained with SNAPCox8A-SiR exhibited strong background in the cytosols (Supplementary Figures 13C,D); (iv) SiR-Actin were bleached very quickly, indicating the insufficient anti-bleaching property of SiR dye itself (Supplementary Figure 13E). The excess over-expression level of the SNAP- protein, which is relatively challenging to control in normal cancer cells and to realize in primary cultural cells, may result in the low image quality in the SNAP-tag technique (Supplementary Figures 13C,D).
However, fluorescent probes are easy to control by simply changing the incubation concentration. The results suggest that Atto 647N exhibited the best photostability (4.66 times the value of MitoTracker Deep Red, and 2.58 times that of SiR dye itself; Figure 3A; Supplementary Figure 13A). By adding antioxidant reagent Prolong Live (Westbrook et al., 2018), all the bleaching speeds of these dyes decelerated to some extent. However, the difference between the dyes remained unchanged (Figure 4A; Supplementary Figure 13)

The performance of Atto $647 \mathrm{~N}$ was further investigated using stimulated emission depletion (STED) microscopy (Figures 4B-E). The distance of mitochondrial outer membranes was resolved as $116 \mathrm{~nm}$ in STED mode, while the confocal image showed blurred structures (Figures 4C,D). Besides, structures of folded inner membranes, cristae, which were arranged in groups, and the voids between them were visible in the STED image (white arrows in Figure 4E) (Han et al., 2017; Huang et al., 2018; Stephan et al., 2019). Therefore, these results indicate that by applying our method in live-cell mitochondrial staining, especially in long-term or super-resolution imaging, Atto $647 \mathrm{~N}$ can substitute SiR dye (Stephan et al., 2019) by offering better optical properties.

\section{Dual-Color Applications}

Dual-color staining combined with either fluorescent proteins (EMTB-3XGFP (Guo et al., 2018); Figure 5A) or other probes (ER-Tracker Green; Figures 5B-D and Supplementary Figure 14) were performed, suggesting the compatibility of our method with other labeling strategies. Longterm dual-color confocal imaging (20-min imaging duration at 2.4-s intervals) was performed in living Astrocytes, based on the excellent optical properties of Atto 647N (Figures 5B-D and Supplementary Figure 14). Interestingly, the results in astrocytes indicate that some of the ER substructures 

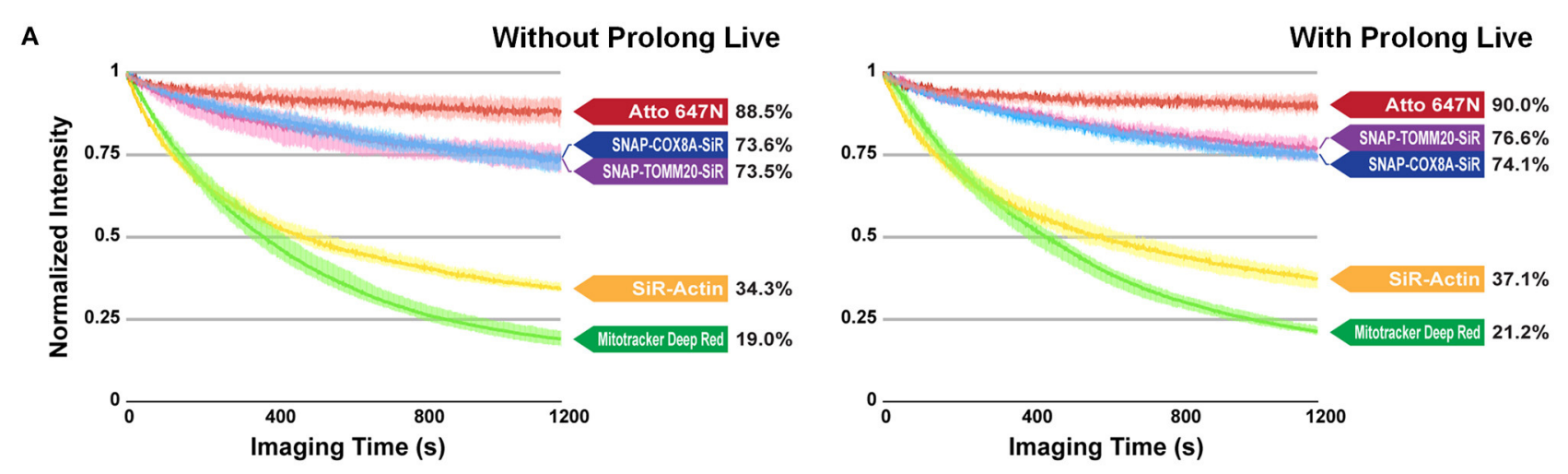

B

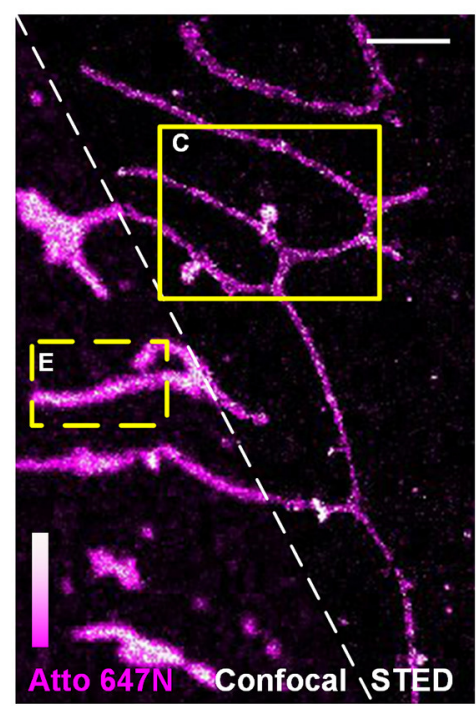

C
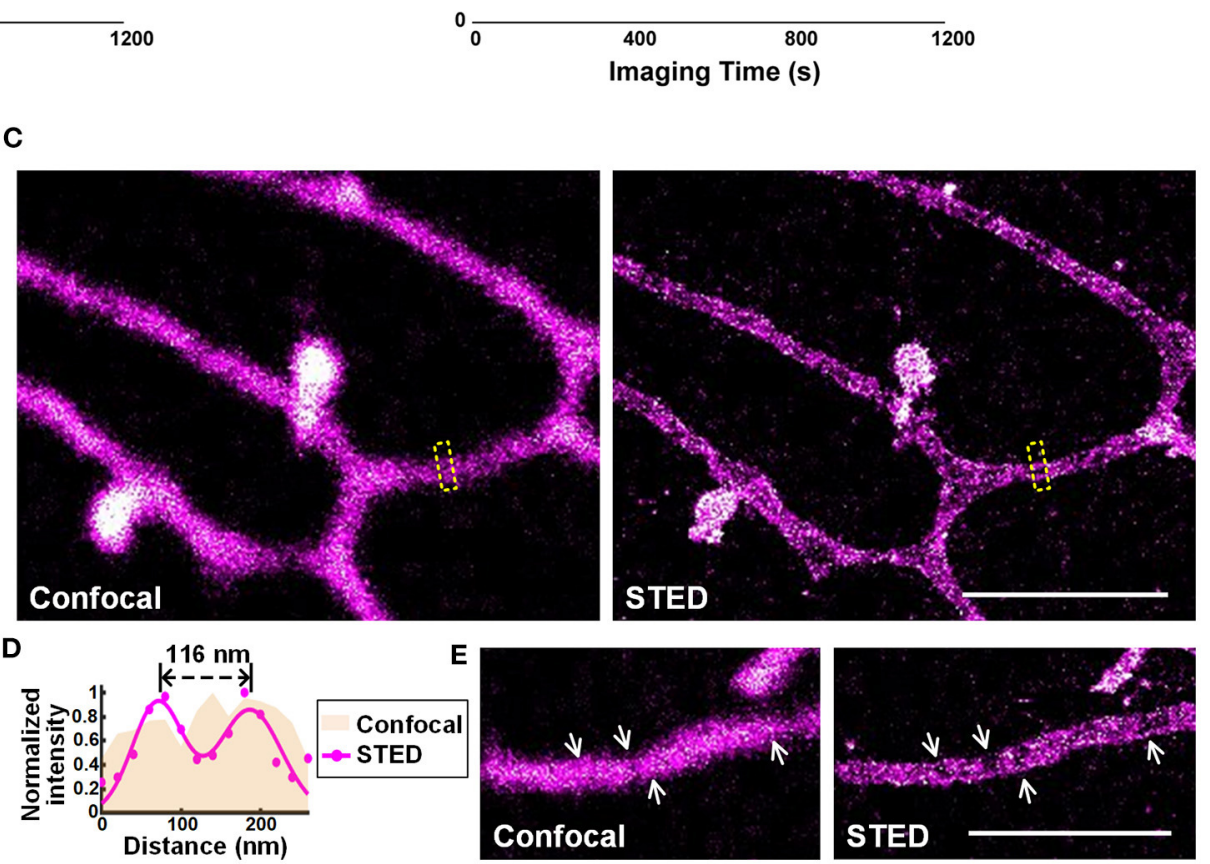

FIGURE 4 | Atto 647N for live-cell imaging applications with high demand for optical properties. (A) Curves of intensity decay of the indicated dyes without (left) or with (right) the addition of Prolong Live under the same confocal imaging condition. Consecutive frames spaced at 1-s intervals were recorded. Error bars represent the standard deviations of triplicate experiments. (B) Living U2OS cells were incubated with Atto $647 \mathrm{~N}$ for $30 \mathrm{~min}$ at $20^{\circ} \mathrm{C}$. Enlarged confocal and STED images from the (C) solid or (E) dashed yellow boxes shown in (B). (D) Intensity profiles at the positions within the dashed boxes in (C) (pink area for the confocal image, and magenta dots and Gaussian fitting curve for STED image). Scale bars, $2 \mu \mathrm{m}$.

colocalized with mitochondria over time (the white and yellow arrowheads in Figure 5B; Supplementary Figure 14A). The possibility of crosstalk between channels was ruled out since there were some places with no overlap of the two channels (highlighted with the yellow arrows in Figure 5B). Moreover, hitchhiking interactions (Guo et al., 2018) between ERmitochondria (Figures 5C,D), ER-vesicles (white arrowheads in Supplementary Figure 14C), and ER themselves (magenta arrowheads in Supplementary Figure 14C) were observed in our experiments.

\section{Labeling Living Tissues}

Compared with typical mammalian cells cultured on coverslips, labeling living tissue samples usually harbor a more significant challenge. Tissues in vitro die soon after losing blood flow support, resulting in mitochondrial potential gradient loss. As a consequence, the cationic dyes cannot affine to mitochondria.
To permit sufficient staining deep into the living tissue, the fluorescent probes should permeate through the tissues fast enough so that they can bind to mitochondria before the gradient is lost. Specifically, the brain slices were incubated with Atto $647 \mathrm{~N}$ immediately after the mice were sacrificed. Our results suggest that 0.5 -h incubation was sufficient for the dye to permeate for at least $20-\mu \mathrm{m}$ thickness, indicating its excellent permeability through tissues (Figure 5E; Supplementary Figures 15A-C). In contrast, MitoTracker Green failed to stain the brain sample (Figure 5F), which suggests the abilities of Atto $647 \mathrm{~N}$ to substitute MitoTracker probes in staining living tissues. Notably, our approach is highly versatile. Besides the brain slices, adipose tissues (Supplementary Figure 15D), blood cells (Supplementary Figure 15E), cardiac and skeletal muscle fibers (Supplementary Figures 15F,G), and embryo slices (Supplementary Figure 15H) were also successfully stained. Compared with the immunofluorescence techniques in previous 


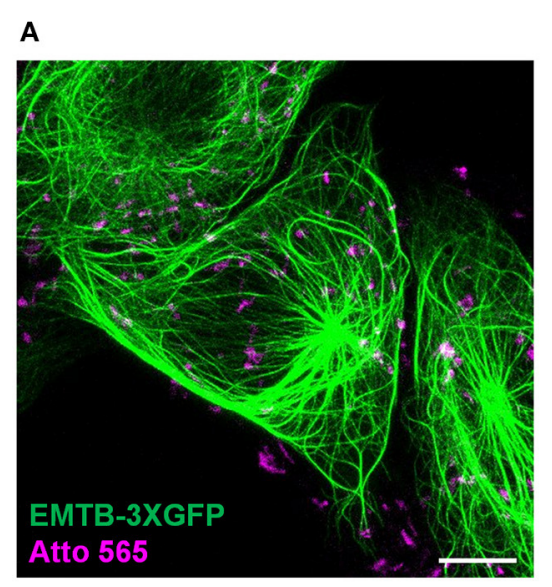

c

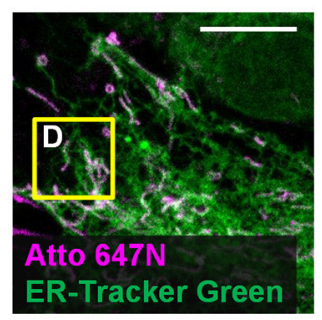

D

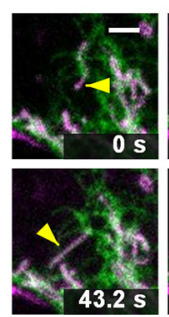

B

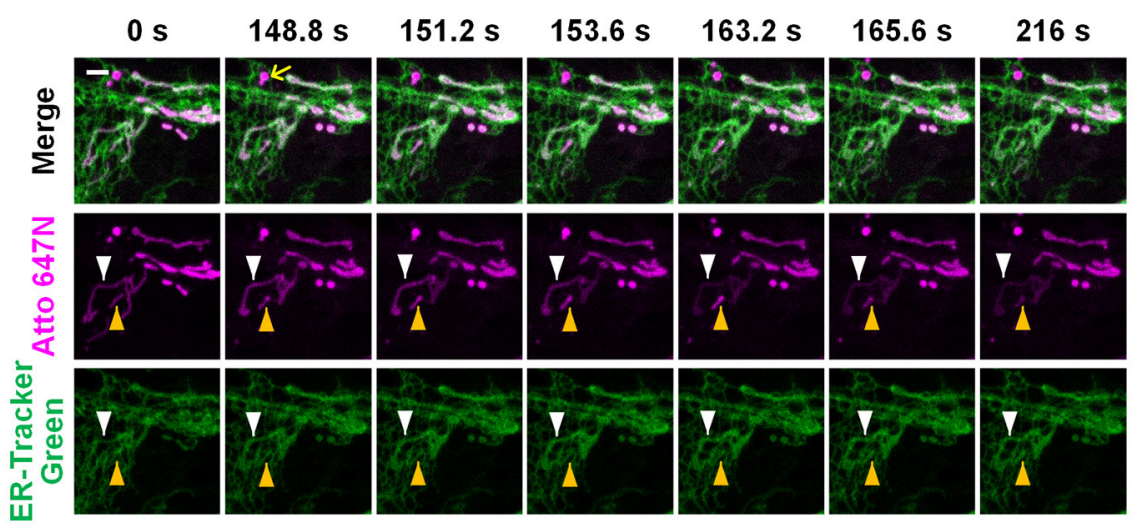

E

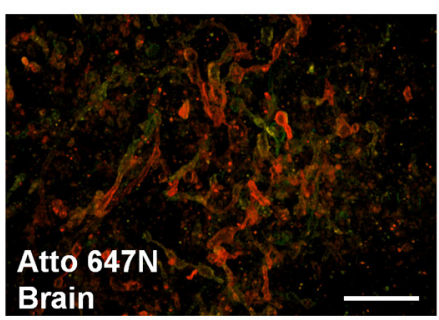

F

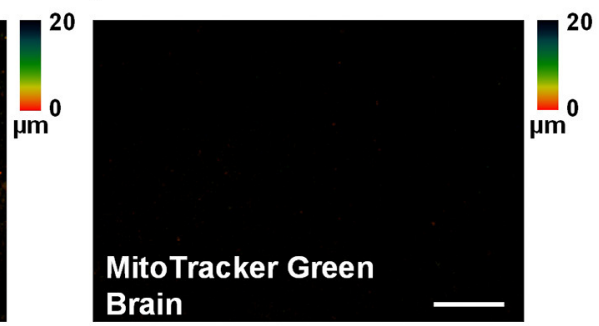

FIGURE 5 | Other applications in living cells and tissues. (A) Dual-color confocal image (maximum intensity projection) of living U2OS cells labeled with EMTB-3XGFP (green) and Atto 565 (magenta; $3 \mu \mathrm{M}$ ). (B,C) Dual-color confocal image of living Astrocytes labeled with Atto 647N (magenta; $15 \mu \mathrm{M}$, middle row) and ER-Tracker Green (green; $2 \mu \mathrm{M}$, bottom row) for $30 \mathrm{~min}$ at $20^{\circ} \mathrm{C}$. (D) Mitochondria move along ER tubules. No deconvolution or bleaching compensation procedure was applied during the figure rendering. For the time-lapse images, consecutive frames spaced at 2.4-s intervals were recorded; representative images of consecutive frames are displayed. Brain slices incubated with (E) Atto 647N and (F) MitoTracker Green. Color bars on the right of (E) and (F) indicate the imaging depth. Scale bars, (A,C) $10 \mu \mathrm{m}, \mathbf{( B , D )} 2 \mu \mathrm{m}$, and (E,F) $20 \mu \mathrm{m}$.

works (Schneider Gasser et al., 2006; Chakrabarty et al., 2018), our method requires convenient and straightforward protocol steps, and direct incubation used here avoids the structural change caused by fixation. Therefore, our method is advantageous for many applications that expect instant actions, such as the rapid medical diagnoses of biospecimen in vitro and assessment for some mitochondrial diseases (Lee et al., 2019).

\section{CONCLUSION}

In summary, the capability of many fluorescent dyes, which was ignored to some extent before, to stain various types of subcellular structures in living specimens with high brightness and photostability is confirmed. Potential targets include mitochondria, ER, endocytic vesicles, and the plasma membrane. The implementation requires only specific incubation conditions without any chemical modification or physical penetration, minimizing the damages and artifacts induced during the sample preparation. Moreover, Atto $647 \mathrm{~N}$ exhibited extraordinary brightness and photostability in live-cell mitochondrial labeling, which can substitute $\mathrm{SiR}$ dye in long-term imaging or super-resolution microscopy.

Due to the limits from objective conditions, especially considering that the structures of many of the commercially available fluorescent dyes are a trade secret, not all of them are tested in this paper. It is worth noting that micromolar-level concentrations of some fluorophores may lead to a potential cytotoxicity to some sensitive cell lines. The organic solvent (e.g., DMSO) in the incubation solutions should also be controlled carefully to balance the dye dissolution and the toxicity to living cells when using new fluorophores. However, the hypothesis that was built in this work provides a guideline to elucidating these candidates and to broaden the applications of existing dyes. Moreover, the phenomena observed here show their great potential in answering a wide range of biological questions in living cells and tissues.

\section{DATA AVAILABILITY STATEMENT}

The raw data supporting the conclusions of this article will be made available by the authors, without undue reservation.

\section{ETHICS STATEMENT}

The animal study was reviewed and approved by Zhejiang University. 


\section{AUTHOR CONTRIBUTIONS}

$\mathrm{XH}, \mathrm{YH}, \mathrm{CK}$, and $\mathrm{XL}$ conceived the project. Experiments were performed primarily by YH. ZZ and WL set up the system and contributed to the imaging. $\mathrm{YH}$ and $\mathrm{YY}$ prepared the samples. $\mathrm{YH}$ and $\mathrm{XH}$ drafted the manuscript. All authors contributed to the manuscript polish. All authors contributed to the article and approved the submitted version.

\section{FUNDING}

This work was financially sponsored by the grants from the National Key R\&D Program of China (2018YFA0701400 and 2018YFE0119000), the National Natural Science Foundation of China (61827825, 61735017, and 31901059), Fundamental Research Funds for the Central Universities (2019XZZX003-06 and 2019QNA5006), China Postdoctoral Science Foundation

\section{REFERENCES}

Bosch, P. J., Correa, I. R. Jr., Sonntag, M. H., Ibach, J., Brunsveld, L., Kanger, J. S., et al. (2014). Evaluation of fluorophores to label SNAP-tag fused proteins for multicolor single-molecule tracking microscopy in live cells. Biophys. J. 107, 803-814. doi: 10.1016/j.bpj.2014.06.040

Chakrabarty, S., Kabekkodu, S. P., Singh, R. P., Thangaraj, K., Singh, K. K., and Satyamoorthy, K. (2018). Mitochondria in health and disease. Mitochondrion 43, 25-29. doi: 10.1016/j.mito.2018.06.006

Chazotte, B. (2011). Labeling mitochondria with MitoTracker dyes. Cold Spring Harb. Protoc. 2011, 990-992. doi: 10.1101/pdb.prot5648

Cory, A. H., Owen, T. C., Barltrop, J. A., and Cory, J. G. (1991). Use of an aqueous soluble tetrazolium formazan assay for cell-growth assays in culture. Cancer Commun. 3, 207-212. doi: 10.3727/095535491820873191

Cottet-Rousselle, C., Ronot, X., Leverve, X., and Mayol, J. F. (2011). Cytometric assessment of mitochondria using fluorescent probes. Cytometry A 79, 405-425. doi: 10.1002/cyto.a.21061

Dutta, D., and Donaldson, J. G. (2012). Search for inhibitors of endocytosis: intended specificity and unintended consequences. Cell. Logist. 2, 203-208. doi: $10.4161 / \mathrm{cl} .23967$

Erazo-Oliveras, A., Najjar, K., Dayani, L., Wang, T. Y., Johnson, G. A., and Pellois, J. P. (2014). Protein delivery into live cells by incubation with an endosomolytic agent. Nat. Methods 11, 861-867. doi: 10.1038/nmeth.2998

Fernandez-Suarez, M., and Ting, A. Y. (2008). Fluorescent probes for superresolution imaging in living cells. Nat. Rev. Mol. Cell Biol. 9, 929-943. doi: $10.1038 / \mathrm{nrm} 2531$

Fujimoto, L. M., Roth, R., Heuser, J. E., and Schmid, S. L. (2000). Actin assembly plays a variable, but not obligatory role in receptor-mediated endocytosis in mammalian cells. Traffic 1, 161-171. doi: 10.1034/j.1600-0854.2000.01 0208.x

Guo, Y., Li, D., Zhang, S., Yang, Y., Liu, J. J., Wang, X., et al. (2018). Visualizing intracellular organelle and cytoskeletal interactions at nanoscale resolution on millisecond timescales. Cell 175, 1430-1442. doi: 10.1016/j.cell.2018.09.057

Han, Y., Li, M., Qiu, F., Zhang, M., and Zhang, Y. H. (2017). Cellpermeable organic fluorescent probes for live-cell long-term super-resolution imaging reveal lysosome-mitochondrion interactions. Nat. Commun. 8:1307. doi: 10.1038/s41467-017-01503-6

Han, Y., Li, M., Zhang, M., Huang, X., Chen, L., Hao, X., et al. (2019). Cellpermeable organic fluorescent probes for live-cell super-resolution imaging of actin filaments. J. Chem. Technol. Biot. 94, 2040-2046. doi: 10.1002/jctb.5990

Han, Y., Zhang, Z., Liu, W., Yao, Y., Chen, Y., Luo, X., et al. (2020). Labeling subcellular structures in living specimens using live-cell incompatible dyes with excellent optical properties. bioRxiv [Preprint] 2020.2005.2010.086538. doi: $10.1101 / 2020.05 .10 .086538$
(2019M662042), Natural Science Foundation of Zhejiang province (LR16F050001), Zhejiang Lab (2018EB0ZX01), and ZJU-Sunny Photonics Innovation Center (2019-01).

\section{ACKNOWLEDGMENTS}

We thank Mr. Yisheng $\mathrm{Wu}$ from SRstar Instruments Ltd., Shanghai, China, for operating the Abberior STEDYCON. This manuscript has been released as a pre-print at bioRxiv (Han et al., 2020).

\section{SUPPLEMENTARY MATERIAL}

The Supplementary Material for this article can be found online at: https://www.frontiersin.org/articles/10.3389/fchem. 2020.601436/full\#supplementary-material
Hennig, S., van de Linde, S., Lummer, M., Simonis, M., Huser, T., and Sauer, M. (2015). Instant live-cell super-resolution imaging of cellular structures by nanoinjection of fluorescent probes. Nano Lett. 15, 1374-1381. doi: $10.1021 / \mathrm{nl} 504660 \mathrm{t}$

Huang, X., Fan, J., Li, L., Liu, H., Wu, R., Wu, Y., et al. (2018). Fast, long-term, super-resolution imaging with Hessian structured illumination microscopy. Nat. Biotechnol. 36, 451-459. doi: 10.1038/nbt.4115

Jaiswal, J. K., Mattoussi, H., Mauro, J. M., and Simon, S. M. (2003). Long-term multiple color imaging of live cells using quantum dot bioconjugates. Nat. Biotechnol. 21, 47-51. doi: 10.1038/nbt767

Ji, N., Freeman, J., and Smith, S. L. (2016). Technologies for imaging neural activity in large volumes. Nat. Neurosci. 19, 1154-1164. doi: 10.1038/nn.4358

Lee, J. H., Park, A., Oh, K. J., Lee, S. C., Kim, W. K., and Bae, K. H. (2019). The role of adipose tissue mitochondria: regulation of mitochondrial function for the treatment of metabolic diseases. Int. J. Mol. Sci. 20:4924. doi: 10.3390/ijms20194924

Lukinavicius, G., Mitronova, G. Y., Schnorrenberg, S., Butkevich, A. N., Barthel, H., Belov, V. N., et al. (2018). Fluorescent dyes and probes for super-resolution microscopy of microtubules and tracheoles in living cells and tissues. Chem. Sci. 9, 3324-3334. doi: 10.1039/C7SC05334G

Lukinavicius, G., Reymond, L., D’Este, E., Masharina, A., Gottfert, F., Ta, H., et al. (2014). Fluorogenic probes for live-cell imaging of the cytoskeleton. Nat. Methods 11, 731-733. doi: 10.1038/nmeth.2972

Lukinavičius, G., Reymond, L., and Johnsson, K. (2015). Site-specific Protein Labeling: Methods and Protocols. New York, NY: Humana Press.

Manceur, A., Wu, A., and Audet, J. (2007). Flow cytometric screening of cellpenetrating peptides for their uptake into embryonic and adult stem cells. Anal. Biochem. 364, 51-59. doi: 10.1016/j.ab.2007.02.015

Mao, C., Lee, M. Y., Jhan, J. R., Halpern, A. R., Woodworth, M. A., Glaser, A. K., et al. (2020). Feature-rich covalent stains for super-resolution and cleared tissue fluorescence microscopy. Sci. Adv. 6:eaba4542. doi: 10.1126/sciadv.aba4542

Mishin, A. S., Belousov, V. V., Solntsev, K. M., and Lukyanov, K. A. (2015). Novel uses of fluorescent proteins. Curr. Opin. Chem. Biol. 27, 1-9. doi: 10.1016/j.cbpa.2015.05.002

Miyawaki, A., Sawano, A., and Kogure, T. (2003). Lighting up cells: labelling proteins with fluorophores. Nat. Cell Biol. 5, 1-2. doi: 10.1038/ncb0103-1

Poot, M., Zhang, Y. Z., Kramer, J. A., Wells, K. S., Jones, L. J., Hanzel, D. K., et al. (1996). Analysis of mitochondrial morphology and function with novel fixable fluorescent stains. J. Histochem. Cytochem. 44, 1363-1372. doi: $10.1177 / 44.12 .8985128$

Rodal, S. K., Skretting, G., Garred, O., Vilhardt, F., van Deurs, B., and Sandvig, K. (1999). Extraction of cholesterol with methyl-beta-cyclodextrin perturbs formation of clathrin-coated endocytic vesicles. Mol. Biol. Cell 10, 961-974. doi: $10.1091 / \mathrm{mbc} \cdot 10.4 .961$ 
Schneider Gasser, E. M., Straub, C. J., Panzanelli, P., Weinmann, O., SassoePognetto, M., and Fritschy, J. M. (2006). Immunofluorescence in brain sections: simultaneous detection of presynaptic and postsynaptic proteins in identified neurons. Nat. Protoc. 1, 1887-1897. doi: 10.1038/nprot.2006.265

Shen, S. L., Zhang, X. F., Ge, Y. Q., Zhu, Y., Lang, X. Q., and Cao, X. Q. (2018). A near-infrared lysosomal $\mathrm{pH}$ probe based on rhodamine derivative. Sensor Actuat. B-Chem. 256, 261-267. doi: 10.1016/j.snb.2017.10.103

Sigal, Y. M., Zhou, R., and Zhuang, X. (2018). Visualizing and discovering cellular structures with super-resolution microscopy. Science 361, 880-887. doi: 10.1126/science.aau1044

Simons, M., Gault, W. J., Gotthardt, D., Rohatgi, R., Klein, T. J., Shao, Y., et al. (2009). Electrochemical cues regulate assembly of the Frizzled/Dishevelled complex at the plasma membrane during planar epithelial polarization. Nat. Cell Biol. 11, 286-294. doi: 10.1038/ncb1836

Specht, E. A., Braselmann, E., and Palmer, A. E. (2017). A critical and comparative review of fluorescent tools for live-cell imaging. Annu. Rev. Physiol. 79, 93-117. doi: 10.1146/annurev-physiol-022516-034055

Stephan, T., Roesch, A., Riedel, D., and Jakobs, S. (2019). Livecell STED nanoscopy of mitochondrial cristae. Sci. Rep. 9:12419. doi: 10.1038/s41598-019-48838-2

von Provazek, S. (1914). Uber fluoreszenz der zellen. Kleinwelt 630.

Westbrook, A. W., Ren, X., Moo-Young, M., and Chou, C. P. (2018). Engineering of cell membrane to enhance heterologous production of hyaluronic acid in Bacillus subtilis. Biotechnol. Bioeng. 115, 216-231. doi: 10.1002/bit.26459

Wories, H. J., Koek, J. H., Lodder, G., Lugtenburg, J., Fokkens, R., Driessen, O., et al. (1985). A novel water-soluble fluorescent-probe - synthesis, luminescence and biological properties of the sodium-salt of the 4 -sulfonato-3, $3^{\prime}, 5,5^{\prime}$ tetramethyl-2,2' -pyrromethen-1,1' -bf2 complex. Recl. Trav. Chim. Pay B 104 288-291. doi: 10.1002/recl.19851041104

Xu, W., Zeng, Z., Jiang, J. H., Chang, Y. T., and Yuan, L. (2016). Discerning the chemistry in individual organelles with small-molecule fluorescent probes. Angew. Chem. Int. Ed Engl. 55, 13658-13699. doi: 10.1002/anie.2015 10721

Yamashiro, D. J., Fluss, S. R., and Maxfield, F. R. (1983). Acidification of endocytic vesicles by an ATP-dependent proton pump. J. Cell Biol. 97, 929-934. doi: $10.1083 /$ jcb.97.3.929

Yang, X., Yang, Z., Wu, Z., He, Y., Shan, C., Chai, P., et al. (2020). Mitochondrial dynamics quantitatively revealed by STED nanoscopy with an enhanced squaraine variant probe. Nat. Commun. 11:3699. doi: $10.1038 /$ s41467-020-17546-1

Conflict of Interest: The authors declare that the research was conducted in the absence of any commercial or financial relationships that could be construed as a potential conflict of interest.

Copyright (C) 2021 Han, Zhang, Liu, Yao, Xu, Liu, Kuang and Hao. This is an open-access article distributed under the terms of the Creative Commons Attribution License (CC BY). The use, distribution or reproduction in other forums is permitted, provided the original author(s) and the copyright owner(s) are credited and that the original publication in this journal is cited, in accordance with accepted academic practice. No use, distribution or reproduction is permitted which does not comply with these terms. 